\title{
An Architecture for Adaptive Robust Modelling of Wildfire Behaviour under Deep Uncertainty
}

\author{
Daniele de Rigo ${ }^{1,2}$, Dario Rodriguez-Aseretto ${ }^{1}$, Claudio Bosco ${ }^{3}$, \\ Margherita Di Leo ${ }^{1}$, and Jesús San-Miguel-Ayanz ${ }^{1}$ \\ 1 European Commission, Joint Research Centre, Institute for Environment and \\ Sustainability, via E. Fermi 2749, I-21027 Ispra (VA), Italy \\ 2 Politecnico di Milano, Dipartimento di Elettronica e Informazione, \\ via Ponzio 34/5, I-20133 Milano, Italy \\ 3 Loughborough University, Department of Civil and Building Engineering \\ Loughborough LE11 3TU, United Kingdom
}

\begin{abstract}
Wildfires in Europe - especially in the Mediterranean region - are one of the major treats at landscape scale. While their immediate impact ranges from endangering human life to the destruction of economic assets, other damages exceed the spatio-temporal scale of a fire event. Wildfires involving forest resources are associated with intense carbon emissions and alteration of surrounding ecosystems. The induced land cover degradation has also a potential role in exacerbating soil erosion and shallow landslides. A component of the complexity in assessing fire impacts resides in the difference between uncontrolled wildfires and those for which a control strategy is applied. Robust modelling of wildfire behaviour requires dynamic simulations under an array of multiple fuel models, meteorological disturbances and control strategies for mitigating fire damages. Uncertainty is associated to meteorological forecast and fuel model estimation. Software uncertainty also derives from the datatransformation models needed for predicting the wildfire behaviour and its consequences. The complex and dynamic interactions of these factors define a context of deep uncertainty. Here an architecture for adaptive and robust modelling of wildfire behaviour is proposed, following the semantic array programming paradigm. The mathematical conceptualisation focuses on the dynamic exploitation of updated meteorological information and the design flexibility in adapting to the heterogeneous European conditions. Also, the modelling architecture proposes a multicriteria approach for assessing the potential impact with qualitative rapid assessment methods and more accurate a-posteriori assessment.
\end{abstract}

Keywords: Wildfire Behaviour, Deep Uncertainty, Integrated Natural Resources Modelling and Management, Semantic Array Programming.

\section{Introduction}

Landscape and ecosystem dynamics show intense interactions with disturbances [1-4]. The complexity and uncertainty associated with these interactions - along with the severity and variety of the involved impacts - urge robust, holistic and

J. Hřebíček et al. (Eds.): ISESS 2013, IFIP AICT 413, pp. 367-380 2013.

(C) IFIP International Federation for Information Processing 2013 
transparent approaches [5]. In Europe [6, wildfires are one of the major treats at landscape scale. Wildfires have a particular impact in the Mediterranean Europe [7-9] while affecting the aerosol load even in Northern part of the continent [10,11]. Whilst their immediate impact ranges from endangering human life to the destruction of economic assets, other damages exceed the spatio-temporal scale of a fire event [9]. This generates a complex network of transdisciplinary relationships. Such connections need to be properly taken into account in order for meaningful wildfire behaviour modelling to be able to support assessment and management at the science-policy interface.

Here, a general modelling conceptualisation of the interactions among wildfire behaviour, related transdisciplinary impacts, fire management and control strategies is proposed. The special focus on the many sources of uncertainty [5, 12] leads to a robust semantically-enhanced modelling architecture based on the paradigm of Semantic Array Programming (SemAP) [13 15]. Arrays of wildfire behaviour models, dynamic information forecasts (i.e. meteorology), static parameterisation (i.e. spatial distribution of fuel) and transdisciplinary impact assessment models (e.g. [17 21]) are considered within a robust ensemble-based architecture.

The concept of Dynamic Data Driven Application Systems (DDDAS) [22 23 is exploited along with a Partial Open Loop Feedback Control (POLFC) approach [24] for mitigating the overall costs associated with fire events by means of an adaptive use of timely available information. Preliminary prototypes of the proposed architecture have been discussed in [9, 25]. The whole architecture is made possible by essentially relying on free software [5, 16, 26, 27] for ensuring semantically enhanced design diversity [12].

\subsection{Transdisciplinary Wildfire Behaviour: Continental Scale INRMM}

Wildfires constitute a direct risk for human life and health [28] while being associated with intense carbon emissions and alteration of surrounding ecosystems [29, 30], from habitat connectivity [31,32] to biodiversity [33]. The induced land cover degradation [34 has also a potential role in exacerbating soil erosion [18, 19, and shallow landslides [17] while altering the precipitation-runoff relationship [35] along with flood regimes [36, 37. Off-site effects [38, 39] such as fire-induced sediment yield in downstream rivers may cause losses in water storage and affect water quality [40,41] and long-range transport of aerosol may induce transboundary effects [10, 11].

Other elements have a role in perturbing large-scale patterns of interactions. Climate change 42 modifies the spatial distribution and habitat suitability of several plant species [5, 43. Along with pest outbreaks, this may alter vegetation response to fire (e.g. changes in deadwood, litter, undergrowth, average moisture) 44. This context of uncertainty 45] and multiplicity of transdisciplinary assessment criteria [46] suggests integrated natural resources modelling and management (INRMM) [4] as an appropriate frame.

The INRMM approach may result even more appropriate when wide and heterogeneous spatial extents are considered, for which a broad variety of environments is expected. This is the case of the continental scale, here addressed 
for Europe. Besides and complementing national scale systems, fire information in Europe can rely on the European Forest Fire Information System (EFFIS) which operates over 30 countries in the European and Mediterranean regions, covering the full cycle of forest fire management [6]. Ongoing research [9, 25] investigates integrated fire behaviour modelling with the help of high resolution meteorological data (e.g. [48, 49]) within a modelling paradigm which exploits geospatial and computational tools [15] for supporting robustness and semantic transparency [5, 12]. This work is set within this exploratory context.

\section{Wildfire Behaviour and Management of Fire-Events}

Wildfire behaviour intensely interacts with the anthropogenic strategies for controlling fire. The complete modelling methodology is presented in section 3. Here, the anthropogenic control for mitigating the fire evolution is focused. Fire control includes broad options for fire suppression or retardation and fuel reduction, which constitute the set $\mathcal{U}^{\mathbf{u}}$ of controls $\mathbf{u}$. (see eq. 2). Many different computational models have long [50] supported wildfire behaviour analysis [51]. The actions for containing the damages of a given fire event may be split in the sequence of controls $\mathbf{u}_{t}, \mathbf{u}_{t+\Delta t}, \cdots$ which are applied before, during and after the fire lifespan $\mathcal{U}^{t}=\left[t_{\text {start }}, t_{\text {end }}\right]$, where $t_{\text {end }}$ itself could be influenced by the controls. For fire event controls, this sequence may be viewed as instantiating a management policy $u(\cdot)$ for the particular event conditions (i.e. the fire state $\mathbf{x}$ ):

$$
\mathbf{u}_{t}, \mathbf{u}_{t+\Delta t}, \cdots \quad \text { such that } \forall \tau \in \mathcal{U}^{t}, \mathbf{u}_{\tau}=u\left(\mathbf{x}_{\tau}\right)
$$

The temporal distance $\Delta t\left(t, \mathbf{x}_{t}\right)$ between subsequent controls could vary depending on the state $\mathbf{x}_{t}$ and the exogenous information available at time $t$. For example, sudden meteorological changes - or approaching highly populated areas - may suggest the need for intensifying the frequency $1 / \Delta t$ of controls. Control policies may either be provided to the wildfire behaviour model as external input or they may be generated within the model. The related control sequences may be concisely expressed as $\mathbf{U}_{t_{1}, t_{2}}^{t}=\left\{\mathbf{u}_{t_{1}}^{t}, \mathbf{u}_{t_{1}+\Delta t}^{t}, \cdots \mathbf{u}_{t_{2}}^{t}\right\} \in \mathcal{U}_{t_{1}, t_{2}}^{\mathbf{u}}$ when they are known at time $t$ and refer to the interval $\left[t_{1}, t_{2}\right]$.

Wildfire Behaviour Simulation with External Control Scenarios. A planned control sequence $\mathbf{U}_{t, t_{\text {end }}}=\left\{\mathbf{u}_{t}^{t}, \mathbf{u}_{t+\Delta t}^{t}, \cdots\right\} \in \mathcal{U}_{t, t_{\text {end }}}^{\mathbf{u}}$ might be passed as model input in $t$ without requiring the model to internally generate it. Here, a series of wildfire control actions is decided elsewhere and notified to the model. The planned sequence is also suitable to be periodically revised as $\mathbf{U}_{t+\Delta t}^{t+\Delta t}$, $t_{\text {end }}$ by exploiting updated information available at time $t+\Delta t$. A posteriori analysis of the already implemented control sequence $\mathbf{U}_{t_{\text {begin }}, t_{\text {end }}}^{\text {hist }}$, or alternative sequences $\mathbf{U}_{t_{\text {begin }}, t_{\text {end }}}^{\text {alt }}, t_{\text {end }}$ which could have been implemented instead - is also possible.

Generating Fire-Event Control Strategies. Instead of externally provided control scenarios, wildfire impacts might be assessed for internally generated fire 
management options $\mathcal{U}_{t}^{\mathbf{u}, t_{\text {end }}}$ so as to explore the huge space of possible alternatives. Approximate optimisation with machine learning and heuristic methods can help to generate reasonable sub optimal candidates. Information updates during an event may suggest iterative re-optimisation for adapting the suggested control strategy to dynamically support the firefighting and emergency operations. At a broader scale, the approach might serve for simulating possible future fires and contributing to a better spatial allocation of fire crews and equipment.

\section{Modelling Methodology}

\subsection{Dynamic Parameterisation and DDDAS}

Fuel, meteorology and topography are known as the fire environment triangle 52 . Fire behaviour is also shaped by temporal changes of some of these factors. Therefore, time has been proposed as an explicit variable inside fire models into the square of fire factors [53,54]. Dynamic Data Driven Application Systems (DDDAS) 23] programmatically exploit data-driven feedbacks for updating the information used as model input (e.g. adaptive estimates of required information via specialised data transformation models, D-TM [12, 13, 15]). This way, each predictive step is associated with a calibration phase for properly handling information updates on the evolving fire system.

\subsection{Uncertainty and Complexity: Semantic Array Programming}

The use of updated information (e.g. real-time) for adapting the management of dynamic systems is the essence of many dynamic/adaptive control strategies [55, 56]. Some strategies allow varying uncertainties - even related to datadriven information - to be explicitely modelled. Disturbances routinely affect environmental systems. They may show nonlinear and complex patterns of relationship outside and within the system's spatial extent. For example, meteorological forecasting is perturbed by regional (short-term) or global (mid-term) climatic conditions as well as by seasonal and interannual variations (long-term).

Adaptive control is frequently exploited for natural resources management [57]. Water resources management widely uses stochastic dynamic programming (SDP) for optimal seasonal allocation of water within reservoirs (as dams or lakes) 58

The growing complexity in forest resources management also increasingly benefits from SDP applications (e.g. fire risk management [59,60]).

Unfortunately, the so called curse of dimensionality has a strong impact on SDP applicability, since SDP demand for computing resources exponentially grows with the number of state variables. Accurate descriptions of complex systems often imply wider dimensionality of the state vector $\mathbf{x}$. Several strategies [56,61 support natural resources applications in mitigating the intractability of complex problems, by e.g. approximating the SDP with modified algorithms [24, 62, 63]. 
The dynamics of a fire event may be described as the D-TM evolution of the system's state $\mathbf{x}$ (the probability for each spatial cell to be a burnt area) in the discrete time interval $\Delta t\left(t, \mathbf{x}_{t}\right)$ with respect to the disturbances $\xi_{t+\Delta t\left(t, \mathbf{x}_{t}\right)}$ (the spatial field of wind speed and direction, humidity, rainfall), the anthropogenic control $\mathbf{u}_{t}$ and the system characteristics (slope, aspect, fuel), parameterised as $\theta_{t}$ in the following equation system which extends the one presented in 9 :

where:

$$
\mathbf{x}_{t+\Delta t\left(t, \mathbf{x}_{t}\right)}=::\left|f\left(\theta_{t}, \mathbf{x}_{t}, \mathbf{u}_{t}, \xi_{t+\Delta t\left(t, \mathbf{x}_{t}\right)}^{\tau}\right)\right|^{\mathrm{sem}}: \because
$$

$$
\begin{array}{llll}
t & \in \mathcal{U}^{t} & \mathbf{x}_{t}=\mathcal{U}_{t}^{\mathbf{x}} & \mathbf{u}_{t} \in \mathcal{U}_{t}^{\mathbf{u}}\left(\mathbf{x}_{t}\right) \\
\xi_{t+\Delta t\left(t, \mathbf{x}_{t}\right)}^{\tau} & \sim \phi\left(\cdot \mid I_{\tau}\right) & \in \mathcal{U}_{t}^{\xi}\left(\mathbf{x}_{t}, \mathbf{u}_{t}, I_{\tau}\right), \tau \in \mathcal{U}^{t} & \theta_{t}=\theta\left(\mathbf{x}_{t}, \mathbf{u}_{t}\right)
\end{array}
$$

which enables modular modelling of legal obligations by just redefining $\mathcal{U}_{t}^{\mathbf{u}}(\cdot)$. The D-TM module $f(\cdot)$ is subject to the semantic checks sem as pre-, postconditions and invariants on inputs, outputs and the D-TM itself [12,64]:

$$
y=::|f(\theta, x, u, \xi)|:: \quad \Leftrightarrow\left\{\begin{array}{l}
y=f(\theta, x, u, \xi) \\
\square \operatorname{sem}(y, f, \theta, x, u, \xi)
\end{array}\right.
$$

The modal/deontic logic operator $\square$ sem means: "it ought to be that sem", where sem is a set of valid array-based semantic constraints (within the semantic array programming paradigm [13,14] ). A few more obvious constraints are exemplified in the next section as active links ::constraint::). The notation for time refers to the instant in which a given quantity will be known without uncertainty. The disturbance vector $\xi_{t+\Delta t\left(t, \mathbf{x}_{t}\right)}^{\tau}$ may be described in terms of a pdf $\phi\left(\cdot \mid I_{\tau}\right)$ - generally a function of the state and control at time $t$, also dependent from the available data-driven information $I_{\tau}$. This notation expresses the uncertainty associated with the disturbances forecast. Depending on the typology of information and on the time $\tau$ in which the information is available, the uncertainty of the predicted disturbances will typically be highly variable.

The controls could either be external inputs - in which case the system's evolution can only be simulated - or be internally generated for supporting decision-making, either in real-time or as off-line assessment. The control problem in this case implements a Partial Open Loop Feedback Control (POLFC) approach [24] for minimising the overall costs associated with the fire event, from the time $t \in \mathcal{U}^{t}$ onwards:

$$
u^{t}(\cdot)=\underset{\mathbf{u} \in \mathcal{U}_{t, t_{\mathrm{end}}}^{\mathbf{u}}}{\arg \min }\left[\mathcal{C}^{1, t} \mathcal{C}^{2, t} \cdots \mathcal{C}^{i, t} \ldots \mathcal{C}^{n, t}\right]
$$

where each $\operatorname{cost} \mathcal{C}^{i, t}$ is linked to an impact assessment criterion (section 4) and is described as a composition of step-wise costs $c_{\tau}^{i}$ which are estimated 
with the data-driven information $I_{t}$ available at time $t$ for the future time $\tau \in$ $\left\{\tau_{0}, \tau_{1}, \cdots \tau_{K}\right\} \equiv\left\{t, t+\Delta t\left(t, \tilde{\mathbf{x}}_{t}\right) \cdots t_{\text {end }}\right\}$ :

$$
\begin{aligned}
\mathcal{C}^{i, t} & =\underset{\xi_{\tau_{1}}^{t}, \cdots \xi_{\tau_{k}}^{t}, \cdots, \xi_{t_{\mathrm{end}}}^{t}}{\mathrm{E}}\left[\left(\sum_{\tau=t \equiv \tau_{0}}^{\tau_{K-1}} c_{\tau}^{i}\left(\tilde{\mathbf{x}}_{\tau}, \mathbf{u}_{\tau}, \xi_{\tau+\Delta t\left(\tau, \tilde{\mathbf{x}}_{\tau}\right)}^{t}\right)\right)+c_{t_{\mathrm{end}}}^{i}\left(\tilde{\mathbf{x}}_{t_{\mathrm{end}}}\right)\right] \\
\tau_{k} & =\tau_{0}+\sum_{\lambda=0}^{k-1} \Delta t\left(\tau_{\lambda}, \tilde{\mathbf{x}}_{\tau_{\lambda}}\right), \quad \tau_{0} \equiv t, \quad \tau_{K} \equiv t_{\mathrm{end}}
\end{aligned}
$$

with $\mathrm{E}$ a statistical operator and $\tilde{\mathbf{x}}_{\tau}$ estimated by iterating eq. 2 from the known state $\mathbf{x}_{t}$ and information $I_{t}$. The time associated with each subscript $k$ of $\tau_{k}$ is a function of the sequence $\tilde{\mathbf{x}}_{\tau_{0}} \cdots \tilde{\mathbf{x}}_{\tau_{k-1}}$. This sequence also depends on a particular disturbance realisation $\xi_{\tau_{1}}^{t} \cdots \xi_{\tau_{k}}^{t}$ among the possible ones whose distribution is shaped at time $t$.

\subsection{Design Diversity: The State Transition Function}

An ensemble approach is proposed for mitigating the software uncertainty [5, 12 ] associated with the state transition function (eq. 2). Although two particular free software simulators are described, the proposed method is general and applicable to other simulators.

FireSim is the first selected simulator. It implements the library FireLib 65] and the Rothermel model [66] by means of a cellular-automata simulator. FireSim is a deterministic parametric and discrete event type simulator structured as a sequential set of D-TMs with a pipeline structure of four stages.

The second selected simulator is implemented in the free software GRASS GIS [67. The model, based on the least cost path algorithm and simulating elliptically anisotropic spread, is implemented in the function r.spread [68], which takes as input the rate of spread (ROS) generated by the function r.ros [69]. This latter computes the ROS following the Rothermel model 66] and is based on the Fortran code by [70]. The direction of the maximum ROS is the vector sum of the forward ROS in wind direction and that in upslope direction. The obtained raster map layers serve as inputs for r.spread.

The two instances of the state transition function (eq. 2) are deterministic. Within each run, the state $\mathbf{x}_{t, c}$ of a given cell $c$ at time $t$ is converted to be a ::binary:1 flag recording whether $c$ is burnt. Ensembling multiple runs of the instances allows an uncertainty analysis to be performed for different scenarios (ensemble inputs might be more general: valid runs are expected to provide

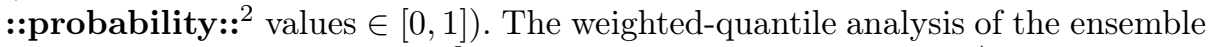

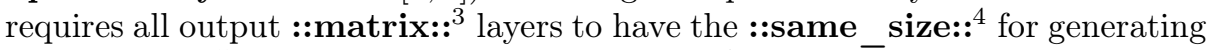
a ::sortable:[ 3 -dimensional array ::3-array: $[$.

\footnotetext{
1 http://mastrave.org/doc/mtv_m/check_is\#SAP_binary

2 http://mastrave.org/doc/mtv_m/check_is\#SAP_probability

3 http://mastrave.org/doc/mtv_m/check_is\#SAP_matrix

4 http://mastrave.org/doc/mtv_m/check_is\#SAP_same_size

5 http://mastrave.org/doc/mtv_m/check_is\#SAP_sortable

6 http://mastrave.org/doc/mtv_m/check_is\#SAP_3-array
} 


\section{Assessing Wildfire Impacts}

Wildfires involving forest resources are associated with intense carbon emissions $(C E)$ and alteration of surrounding ecosystems. Forest fires can affect many different soil properties (chemical, mineralogical and biological) [71. Soil properties, jointly with vegetation cover and hydrology are among the main factors influencing the relation fires - geomorphic processes.

High-severity wildfire, can induce soil water repellency and reduce infiltration capacity [71,72]. Soil hydrophobicity together with the reduced ground cover has been postulated as one of the main causes of soil erosion $(S E)$ and runoff increasing in after-burn areas 73,74 . The reduced ground cover is also responsible of a reduced root strength affecting the soil cohesion and of a reduced leaf area evapotranspiration affecting the soil water level [74. This change in hydrological condition is the main triggering factor for landslide initiation. Soil erosion and landslide susceptibility $(L S)$ can then be considerably increased by wildfires.

The impact of landslide susceptibility $\mathcal{C}^{L S, t}$ and soil erosion $\mathcal{C}^{S E, t}$ (eq. 5) are mostly determined by their post-fire component $c_{t_{\text {end }}}^{i}\left(\tilde{\mathbf{x}}_{t_{\text {end }}}\right), i \in\{L S, E S\}$ (eq. 6) while the impact of wildfire carbon emissions is substantially determined by the step-wise $\operatorname{costs} c_{t}^{C E}\left(\tilde{\mathbf{x}}_{t}, \mathbf{u}_{t}, \xi_{t+\Delta t\left(t, \tilde{\mathbf{x}}_{t}\right)}^{t}\right)$ and shaped not only by the initial spatial distribution of carbon stock [20] but also by the pattern of fire intensity.

A fast computational modelling is required for the rapid assessment of carbon emissions, soil erosion and landslide susceptibility in burnt areas. Physically based models can in principle be more suitable for being applied in areas presenting complex characteristics without any possibility for model calibration. The gap between the number and accuracy of the required input parameters is a limit, therefore complex physically based models are generally inapplicable. Empirical models and less data demanding conceptual models might provide a robust preliminary assessments of post-fire soil erosion and landslide susceptibility. The landslide susceptibility has been calculated by applying a deterministic model (SINMAP) 75,76 based on the infinite slope equation. A modified version of the Revised Universal Soil Loss Equation (e-RUSLE) [18, 19] has been applied for evaluating pre- and post-fire soil erosion.

Landslide Susceptibility. In SINMAP a topographically based steady-state hydrological model is linked with the infinite slope model for evaluating stability conditions. The model applies to shallow translational landslides triggered by water. The slope stability analysis is governed, within the model, by calculating slope and specific catchment areas starting from a Digital elevation model. The input parameters of SINMAP follow a uniform distribution between an upper and lower limit. Because of the flexibility of its input parameters SINMAP can be considered as a suitable model for a rapid slope stability assessment. Further studies are still ongoing for overcoming the limits of the SINMAP approach. A more accurate aposteriori analysis is proposed in [17] where a new fuzzy ensemble is applied for aggregating an array of different landslide susceptibility models. 


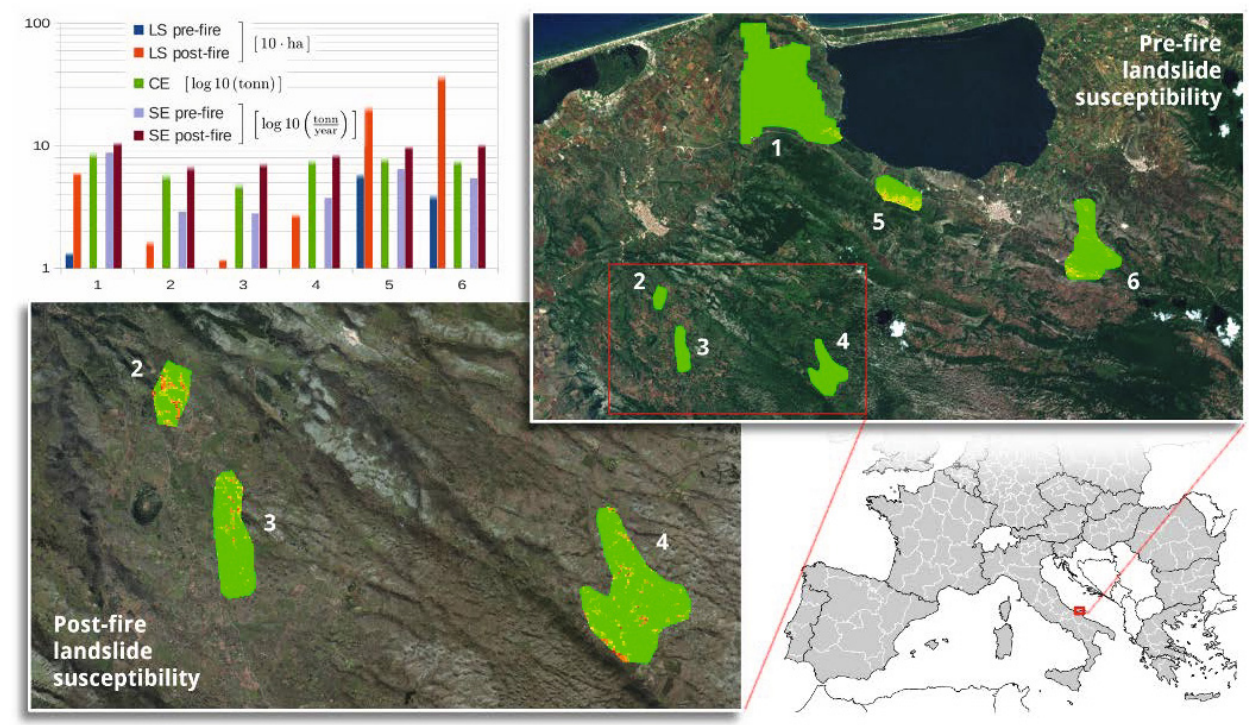

Fig. 1. Rapid assessment of fire carbon emission (CE), pre- and post-fire shallow landslide susceptibility (LS) and water soil erosion (SE) in Northern Puglia (Italy)

Soil Erosion. The e-RUSLE is based on an architecture designed for easing the integration of erosion-related natural resources models. The semantic array programming paradigm [13, 14] and the computational reproducibility [19, 77] are at the basis of the applied modelling architecture. Its flexibility, low data demanding and architecture make the model as one of the best option for rapid post-fire analysis. The e-RUSLE has been applied, for a rapid assessment, using only public available datasets [18,78]. For a more accurate a-posteriori assessment, remote sensing techniques might be applied. The changes in vegetation cover could be better analysed by estimating vegetation indexes as NDVI or fAPAR [79]. Furthermore the soil erosion models based on the USLE provide long term erosion averages and have been applied in many different environments and climatic conditions in numerous countries 80 82. A rapid assessment for the interval of uncertainty associated with the post-fire soil erosion is provided by the DerBos nondimensionalised equation 7. It describes a RUSLE based lower- and upper-bound for the expected soil erosion:

$$
\frac{E_{c}^{\text {burnt }}}{E_{c}^{\text {pot }}}=\left\{\begin{array}{lc}
\max \left(\min \left(1, C_{c}^{\alpha} \frac{K P_{c}^{\text {burnt }}}{K P_{c}^{\text {pre }}}\right), \frac{E_{c}^{\text {pre }}}{E_{c}^{\text {pot }}}\right) & \begin{array}{lc}
\text { max. } \\
\operatorname{estimation}
\end{array} \\
\min \left(1, \max \left(C_{c}^{\beta} \frac{K P_{c}^{\text {burnt }}}{K P_{c}^{\text {pre }}}, \frac{E_{c}^{\text {pre }}}{E_{c}^{\text {pot }}}\right), C_{c}^{\gamma} \frac{K P_{c}^{\text {burnt }}}{K P_{c}^{\text {pre }}}\right) & \text { min. } \\
\text { estimation }
\end{array}\right.
$$


where subscripts refer to a given spatial cell $c$ and the variables are defined as:

$\begin{array}{llllll}E_{c}^{\text {pre }} & : & \text { pre-fire soil erosion } & K_{c}^{\text {pre }} & : & \text { pre-fire K factor } \\ E_{c}^{\text {pot }} & : & \text { potential soil erosion } & K_{c}^{\text {burnt }} & : & \text { post-fire K factor } \\ E_{c}^{\text {burnt }} & : & \text { post-fire soil erosion } & P_{c}^{\text {pre }} & : & \text { pre-fire P factor } \\ C_{c}^{\alpha}, C_{c}^{\beta}, C_{c}^{\gamma}: & \text { post-fire C factors } & P_{c}^{\text {burnt }}: & : & \text { post-fire P factor } \\ K P_{c}^{\text {pre }} & : & K_{c}^{\text {pre }} \cdot P_{c}^{\text {pre }} & K P_{c}^{\text {burnt }}: & K_{c}^{\text {burnt }} \cdot P_{c}^{\text {burnt }}\end{array}$

$C_{c}^{\alpha}, C_{c}^{\beta}, C_{c}^{\gamma}$ are dimensionless factors representing a ::proportion: $] \in\left[\begin{array}{ll}0 & 1\end{array}\right]$ and their values must be ordered in descending order (::sorted-descend: $\beta$ ) so as to have $C_{c}^{\alpha} \geq C_{c}^{\beta} \geq C_{c}^{\gamma}$. $C_{c}^{\alpha}$ represents the maximum degradation of the cover factor due to the wildfire. $C_{c}^{\beta}$ and $C_{c}^{\gamma}$ describe the C-factor minimum expected degradation. While $C_{c}^{\beta}$ generally worsens $E_{c}^{\text {burnt }}$ versus $E_{c}^{\text {pre }}$ where $\frac{E_{c}^{p r e}}{E_{c}^{p o t}}$ is low, $C_{c}^{\gamma}$ may even cause the post-fire erosion to be less than the prefire one in already high-exposed areas in which $E_{c}^{\text {pre }}$ was close to the potential erosion (A substantial ash deposition covering the soil after a fire can reduce the splash detachment and the surface runoff [83]). The ratios $\frac{E_{c}^{\text {pre }}}{E_{c}^{\text {pot }}}$ and $\frac{E_{c}^{\text {burnt }}}{E_{c}^{\text {pot }}}$ are also ::proportion::s $\in\left[\begin{array}{ll}0 & 1\end{array}\right]$.

Carbon Emission. Wildfire carbon emission in a given spatial cell $c$ depends on the overall amount of carbon (total fuel load) and on the local characteristics of fuel (e.g. dead and live fuel, woody and herbaceous one, typical diameters of these fuels) 84. Also, each component of the a given fuel class is associated with a specific burning efficiency and emission factor for estimating $\mathrm{CO}_{2}$ releases in atmosphere which may vary for flaming or smoldering fire [84. The availability of spatially distributed estimations of carbon stock is essential so as to avoid basing $C E$ assessments on rough approximations with fixed conversion factors for each fuel class. The recent pan-European map of living forest carbon stock at IPCC Tier 1 level [20] has been used for integrating the method of [84] with a better spatialisation of $C E$ rapid assessment.

\section{Conclusions}

A flexible architecture for adaptive and robust modelling of wildfire behaviour is proposed, following the semantic array programming paradigm [13, 14]. It relies on an array-based and semantically enhanced application of the dynamic data driven application systems [22,23] for addressing dynamic simulations under an array of multiple fuel models, meteorological disturbances and control strategies for mitigating fire damages.

The mathematical conceptualisation focuses on the dynamic exploitation of updated meteorological information and the design flexibility in adapting to the heterogeneous European conditions. Uncertainty is associated to meteorological forecast and fuel model estimation. Software uncertainty [5,12] is also considered

\footnotetext{
7 http://mastrave.org/doc/mtv_m/check_is\#SAP_proportion

8 http://mastrave.org/doc/mtv_m/check_is\#SAP_sorted-descend
} 
in the data-transformation models needed for predicting the wildfire behaviour and its consequences. The complex and dynamic interactions of these factors define a context of deep uncertainty [5] whose proposed mitigation is based on robust ensembling.

The modelling architecture proposes a multi-criteria approach for assessing potential wildfire impacts with qualitative rapid assessment methods and more accurate a-posteriori assessment. The rapid assessment of soil erosion, landslide susceptibility and carbon emissions is discussed and exemplified.

\section{References}

1. Bengtsson, J., Nilsson, S.G., Franc, A., Menozzi, P.: Biodiversity, disturbances, ecosystem function and management of European forests. For. Ecol. Manage. 132(1), 39-50 (2000)

2. Turner, M.G.: Landscape ecology: What is the state of the science? Annu. Rev. Ecol. Evol. Syst. 36(1), 319-344 (2005)

3. Turner, M.G.: Disturbance and landscape dynamics in a changing world. Ecology 91(10), 2833-2849 (2010)

4. Seidl, R., Fernandes, P.M., Fonseca, T.F., Gillet, F., Jönsson, A.M., et al.: Modelling natural disturbances in forest ecosystems: a review. Ecol. Model. 222(4), 903-924 (2011)

5. de Rigo, D.: Behind the horizon of reproducible integrated environmental modelling at European scale: ethics and practice of scientific knowledge freedom. F1000 Research (submitted 2013)

6. San-Miguel-Ayanz, J., Schulte, E., Schmuck, G., Camia, A., Strobl, P., et al.: Comprehensive Monitoring of Wildfires in Europe: The European Forest Fire Information System (EFFIS). In: Tiefenbacher, J. (ed.) Approaches to Managing Disaster - Assessing Hazards, Emergencies and Disaster Impacts, ch. 5. InTech (2012)

7. Díaz-Delgado, R., Lloret, F., Pons, X., Terradas, J.: Satellite evidence of decreasing resilience in Mediterranean plant communities after recurrent wildfires. Ecology 83(8), 2293-2303 (2002)

8. Pausas, J.G., Llovet, J., Rodrigo, A., Vallejo, R.: Are wildfires a disaster in the Mediterranean basin? - a review. Int. J. Wildland Fire 17(6), 713+ (2008)

9. Rodriguez-Aseretto, D., de Rigo, D., Di Leo, M., Cortés, A., San-Miguel-Ayanz, J.: A data-driven model for large wildfire behaviour prediction in Europe. Procedia Computer Science 18, 1861-1870 (2013)

10. Barnaba, F., Angelini, F., Curci, G., Gobbi, G.P.: An important fingerprint of wildfires on the European aerosol load. Atmos. Chem. Phys. 11(20), 10487-10501 (2011)

11. Saarikoski, S., Hillamo, R.: Wildfires as a source of aerosol particles transported to the northern european regions. In: The Handbook of Environmental Chemistry, pp. 1-21. Springer, Heidelberg (2012)

12. de Rigo, D.: Software Uncertainty in Integrated Environmental Modelling: the role of Semantics and Open Science. Geophys. Res. Abstr. 15, 13292+ (2013)

13. de Rigo, D.: Semantic Array Programming for Environmental Modelling: Application of the Mastrave Library. In: Int. Congress on Environmental Modelling and Software. Managing Resources of a Limited Plant, Pathways and Visions under Uncertainty, Sixth Biennial Meeting, pp. 1167-1176 (2012) 
14. de Rigo, D.: Semantic array programming with Mastrave - introduction to semantic computational modelling (2012)

15. de Rigo, D., Corti, P., Caudullo, G., McInerney, D., Di Leo, M., San Miguel-Ayanz, J.: Toward Open Science at the European Scale: Geospatial Semantic Array Programming for Integrated Environmental Modelling. Geophys. Res. Abstr. 15, $13245+(2013)$

16. de Rigo, D., Guariso, G.: Rewarding Open Science: A Collaborative Review System for Semantically-Enhanced Free Software and Environmental Data Modelling (in prep., 2013)

17. Bosco, C., de Rigo, D., Dijkstra, T., Sander, G., Wasowski, J.: Multi-Scale Robust Modelling of Landslide Susceptibility: Regional Rapid Assessment and Catchment Robust Fuzzy Ensemble. In: Hřebíček, J., Schimak, G., Kubásek, M., Rizzoli, A. (eds.) ISESS 2013. IFIP AICT, vol. 413, pp. 321-335. Springer, Heidelberg (2013)

18. Bosco, C., de Rigo, D., Dewitte, O., Poesen, J., Panagos, P.: Modelling Soil Erosion at European Scale. Towards Harmonization and Reproducibility (in prep.)

19. de Rigo, D., Bosco, C.: Architecture of a pan-european framework for integrated soil water erosion assessment. In: Hřebíček, J., Schimak, G., Denzer, R. (eds.) ISESS 2011. IFIP AICT, vol. 359, pp. 310-318. Springer, Heidelberg (2011)

20. de Rigo, D., Barredo, J.I., Busetto, L., Caudullo, G., San-Miguel-Ayanz, J.: Continental-Scale Living Forest Biomass and Carbon Stock: a Robust Fuzzy Ensemble of IPCC Tier 1 Maps for Europe. In: Hřebíček, J., Schimak, G., Kubásek, M., Rizzoli, A. (eds.) ISESS 2013. IFIP AICT, vol. 413, pp. 271-284. Springer, Heidelberg (2013)

21. Barredo, J.I., San-Miguel-Ayanz, J., Caudullo, G., Busetto, L.: A European map of living forest biomass and carbon stock. In: Reference Report by the Joint Research Centre of the European Commission. EUR - Scientific and Technical Research, vol. $25730(2012)$

22. Darema, F.: Dynamic Data Driven Applications Systems: A New Paradigm for Application Simulations and Measurements. In: Bubak, M., van Albada, G.D., Sloot, P.M.A., Dongarra, J. (eds.) ICCS 2004. LNCS, vol. 3038, pp. 662-669. Springer, Heidelberg (2004)

23. Denham, M., Cortés, A., Margalef, T., Luque, E.: Applying a Dynamic Data Driven Genetic Algorithm to Improve Forest Fire Spread Prediction. In: Bubak, M., van Albada, G.D., Dongarra, J., Sloot, P.M.A. (eds.) ICCS 2008, Part III. LNCS, vol. 5103, pp. 36-45. Springer, Heidelberg (2008)

24. Castelletti, A., de Rigo, D., Tepsich, L., Soncini-Sessa, R., Weber, E.: On-Line design of water reservoir policies based on inflow prediction. IFAC-PapersOnLine 17, 14540-14545 (2008)

25. Di Leo, M., de Rigo, D., Rodriguez-Aseretto, D., Bosco, C., Petroliagkis, T., Camia, A., San-Miguel-Ayanz, J.: Dynamic Data Driven Ensemble for Wildfire Behaviour Assessment: A Case Study. In: Hřebíček, J., Schimak, G., Kubásek, M., Rizzoli, A. (eds.) ISESS 2013. IFIP AICT, vol. 413, pp. 11-22. Springer, Heidelberg (2013)

26. Stallman, R.M.: Viewpoint: Why "open source" misses the point of free software. Commun. ACM 52(6), 31-33 (2009)

27. Rodriguez Aseretto, D., Di Leo, M., de Rigo, D., Corti, P., McInerney, D., et al.: Free and Open Source Software underpinning the European Forest Data Centre. Geophys. Res. Abstr. 15, 12101+ (2013)

28. Richardson, L.A., Champ, P.A., Loomis, J.B.: The hidden cost of wildfires: Economic valuation of health effects of wildfire smoke exposure in southern California. J. For. Econ. 18(1), 14-35 (2012) 
29. Herrando, S., Brotons, L., Llacuna, S.: Does fire increase the spatial heterogeneity of bird communities in Mediterranean landscapes? Ibis 145(2), 307-317 (2003)

30. Torre, I., Díaz, M.: Small mammal abundance in Mediterranean post-fire habitats: a role for predators? Acta Oecologica 25(3), 137-142 (2004)

31. Estreguil, C., Caudullo, G., de Rigo, D., Whitmore, C., San-Miguel-Ayanz, J.: Reporting on European forest fragmentation: Standardized indices and web map services. IEEE Earthzine 5(2), 384031+ (2012); 2nd quarter theme: Forest Resource Information

32. Estreguil, C., Caudullo, G., de Rigo, D., San-Miguel-Ayanz, J.: Forest landscape in Europe: pattern, fragmentation and connectivity. EUR - Scientific and Technical Research 25717(JRC 77295) (2013)

33. Moreira, F., Russo, D.: Modelling the impact of agricultural abandonment and wildfires on vertebrate diversity in Mediterranean Europe. Landsc. Ecol. 22(10), 1461-1476 (2007)

34. Di Piazza, G.V., Di Stefano, C., Ferro, V.: Modelling the effects of a bushfire on erosion in a mediterranean basin. Hydrol. Sci. J. 52(6), 1253-1270 (2007)

35. Moody, J.A., Martin, D.A., Haire, S.L., Kinner, D.A.: Linking runoff response to burn severity after a wildfire. Hydrol. Proces. 22(13), 2063-2074 (2008)

36. Candela, A., Aronica, G., Santoro, M.: Effects of forest fires on flood frequency curves in a Mediterranean catchment. J. Hydrol. Sci. 50(2), 193-206 (2005)

37. Rulli, M.C., Rosso, R.: Hydrologic response of upland catchments to wildfires. Adv. Water Resour. 30(10), 2072-2086 (2007)

38. Ice, G.G., Neary, D.G., Adams, P.W.: Effects of wildfire on soils and watershed processes. J. Forestry 102(6), 16-20 (2004)

39. Shakesby, R., Doerr, S.: Wildfire as a hydrological and geomorphological agent. Earth Sci. Rev. 74(3-4), 269-307 (2006)

40. Smith, H.G., Sheridan, G.J., Lane, P.N.J., Nyman, P., Haydon, S.: Wildfire effects on water quality in forest catchments: a review with implications for water supply. J. Hydrol. 396(1-2), 170-192 (2011)

41. Smith, H.G., Blake, W.H., Owens, P.N.: Discriminating fine sediment sources and the application of sediment tracers in burned catchments: a review. Hydrol. Proces. 27(6), 943-958 (2013)

42. Krawchuk, M.A., Moritz, M.A., Parisien, M.-A., Van Dorn, J., Hayhoe, K.: Global pyrogeography: the current and future distribution of wildfire. PLoS ONE 4(4), $\mathrm{e} 5102+(2009)$

43. Pautasso, M., Dehnen-Schmutz, K., Holdenrieder, O., Pietravalle, S., Salama, N., et al.: Plant health and global change some implications for landscape management. Biol. Rev. 85(4), 729-755 (2010)

44. Nijhuis, M.: Forest fires: Burn out. Nature 489(7416), 352-354 (2012)

45. Hou, Y., Burkhard, B., Müller, F.: Uncertainties in landscape analysis and ecosystem service assessment. J. Env. Manag. (2013)

46. Spangenberg, J.H., Settele, J.: Precisely incorrect? Monetising the value of ecosystem services. Ecol. Complex. 7(3), 327-337 (2010)

47. de Rigo, D.: Integrated Natural Resources Modelling and Management: minimal redefinition of a known challenge for environmental modelling. Excerpt from the Call for a Shared Research Agenda Toward Scientific Knowledge Freedom, Maieutike Research Initiative (2012)

48. Hollingsworth, A., Engelen, R., Textor, C., Benedetti, A., Boucher, O., et al.: Toward a monitoring and forecasting system for atmospheric composition. Bull. Amer. Meteor. Soc. 89(8), 1147-1164 (2008) 
49. Bouttier, F.: The Météo-France NWP system: description, recent changes and plans. CNRM (2010)

50. Perry, G.L.W.: Current approaches to modelling the spread of wildland fire: Areview. Prog. Phys. Geogr. 22(2), 222-245 (1998)

51. Andrews, P., Finney, M., Fischetti, M.: Predicting wildfires. Sci. American 297(2), 46-55 (2007)

52. Countryman, C.M.: The concept of fire environment. Fire Manag. Today 64(1), 49-52 (2004)

53. Viegas, D.X.: Parametric study of an eruptive fire behaviour model. Int. J. Wildland Fire $15(2), 169+(2006)$

54. Rodriguez Aseretto, R., Cortés, A., Margalef, T., Luque, E.: An Adaptive System for Forest Fire Behavior Prediction. In: 11th IEEE Int. Conf. on Computational Science and Engineering, CSE 2008, pp. 275-282 (2008)

55. Bellman, R., Kalaba, R.: On adaptive control processes. IRE Transactions on Autom. Control 4(2), 1-9 (1959)

56. Wang, F.-Y., Zhang, H., Liu, D.: Adaptive Dynamic Programming: An Introduction. IEEE Computational Intell. Mag. 4(2), 39-47 (2009)

57. Lara, M., Doyen, L.: Sustainable Management of Natural Resources: Mathematical Models and Methods. Springer (2008)

58. Rani, D., Moreira, M.: Simulation-Optimization Modeling: A Survey and Potential Application in Reservoir Systems Operation. Water Resour. Manag. 24(6), 1107-1138 (2010)

59. Ferreira, L., Constantino, M.F., Borges, J.G., Garcia-Gonzalo, J.: A Stochastic Dynamic Programming Approach to Optimize Short-Rotation Coppice Systems Management Scheduling: An Application to Eucalypt Plantations under Wildfire Risk in Portugal. Forest Sci. 58(4), 353-365 (2012)

60. Minas, J.P., Hearne, J.W., Handmer, J.W.: A review of operations research methods applicable to wildfire management. Int. J. Wildland Fire 21(3), 189+ (2012)

61. Lee, J.M., Lee, J.H.: Approximate dynamic programming strategies and their applicability for process control: a review and future directions. Int. J. Control Autom. Syst. 2(3), 263-278 (2004)

62. de Rigo, D., Rizzoli, A.E., Soncini-Sessa, R., Weber, E., Zenesi, P.: Neuro-dynamic programming for the efficient management of reservoir networks. In: Proceedings of MODSIM 2001, Int. Congress on Modelling and Simulation Held in Canberra, Australia, vol. 4, pp. 1949-1954 (2001) ISBN: 0-867405252

63. de Rigo, D., Castelletti, A., Rizzoli, A.E., Soncini-Sessa, R., Weber, E.: A selective improvement technique for fastening neuro-dynamic programming in water resources network management. IFAC-PapersOnLine 16, 7-12 (2005)

64. de Rigo, D.: Applying semantic constraints to array programming: the module "check_is" of the Mastrave modelling library. Mastrave Project Technical Report (2011)

65. Bevins, C.D.: FireLib user manual and technical reference. Systems for Environmental Management (1996)

66. Rothermel, R.: How to predict the spread and intensity of forest and range fires. US Department of Agriculture, Forest Service, Intermountain Forest and Range Experiment Station, Ogden (1983)

67. Neteler, M., Bowman, M.H., Landa, M., Metz, M.: GRASS GIS: A multi-purpose open source GIS. Environmental Modelling \& Software 31, 124-130 (2012)

68. Xu, J., Lathrop, R.G.: GRASS GIS manual: r.spread. In: GRASS GIS 6.4.3svn Reference Manual (2006) 
69. Xu, J.: GRASS GIS manual: r.ros. In: GRASS GIS 6.4.3svn Reference Manual (2009)

70. Andrews, P., LLoyd, P.: Fire modeling and information system technology. Int. J. Wildland Fire 10(4), 343-352 (2001)

71. Certini, G.: Effects of fire on properties of forest soils: A review. Oecologia 143, $1-10(2005)$

72. DeBano, L.F.: The role of fire and soil heating on water repellency in wildland environments: A review. J. Hydrol. 231-232, 195-206 (2000)

73. Letey, J.: Causes and consequences of fire-induced soil water repellency. Hydrol. Processes 15, 2867-2875 (2001)

74. Swanson, F.J.: Fire and Geomorphic Processes. In: Gen. Tech. Rep. USDA For. Serv. WO-26. Washington DC. pp. 401-420 (1981)

75. Pack, R.T., Tarboton, D.G., Goodwin, C.N.: The SINMAP Approach to Terrain Stability Mapping. In: 8th Congress of the International Association of Engineering Geology, Vancouver, British Columbia, Canada (1998)

76. Pack, R.T., Tarboton, D.G., Goodwin, C.N., Prasad, A.: SINMAP 2. A Stability Index Approach to Terrain Stability Hazard Mapping, technical description and users guide for version 2.0. Utah State University (2005)

77. Bosco, C., de Rigo, D., Dewitte, O., Montanarella, L.: Towards the reproducibility in soil erosion modeling: a new Pan-European soil erosion map. In: Wageningen conference on applied soil science: 'Soil Science in a Changing World, p. 209+ (2011)

78. Panagos, P., Jones, A., Bosco, C., Senthil Kumar, P.S.: European digital archive on soil maps (EuDASM): preserving important soil data for public free access. Int. J. of Digital Earth 4(5), 434-443 (2011)

79. Myneni, R.B., Williams, D.L.: On the relationship between FAPAR and NDVI. Remote Sensing of Environment 49(3), 200-211 (1994)

80. Kinnell, P.I.A.: Event soil loss, runoff and the Universal Soil Loss Equation family of models: A review. Journal of Hydrology 385, 384-397 (2010)

81. Angima, S.D., Stott, D.E., O’Neill, M.K., Ong, C.K., Weesies, G.: Soil erosion prediction using RUSLE for central Kenyan highland conditions. Agriculture Ecosystems and Environment 97, 295-308 (2003)

82. Bosco, C., Rusco, E., Montanarella, L., Panagos, P.: Soil erosion in the Alpine area: risk assessment and climate change. Studi Trent. Sci. Nat. 85, 117-123 (2009)

83. Cerdá, A., Doerr, S.H.: The effect of ash and needle cover on surface runoff and erosion in the immediate post-fire period. Catena 74, 256-263 (2008)

84. Barbosa, P., Camia, A., Kucera, J., Libertà, G., Palumbo, I., San-Miguel-Ayanz, J., Schmuck, G.: Assessment of Forest Fire Impacts and Emissions in the European Union Based on the European Forest Fire Information System. Developments in Environmental Science 8, 197-208 (2008) 